\title{
A germline PALB2 pathogenic variant identified in a pediatric high-grade glioma
}

\author{
Yiming Zhong, ${ }^{1,2}$ Jeffrey Schubert, ${ }^{1}$ Jinhua Wu, ${ }^{1}$ Feng Xu, ${ }^{1}$ Fumin Lin,${ }^{1}$ Kajia Cao, \\ Kristin Zelley, ${ }^{3}$ Minjie Luo, ${ }^{1,2}$ Jessica B. Foster, ${ }^{2,3}$ Kristina A. Cole, ${ }^{2,3}$ \\ Suzanne P. MacFarland, ${ }^{2,3}$ Adam C. Resnick, ${ }^{1,2,4}$ Phillip B. Storm, ${ }^{1,2,4}$ \\ and Marilyn M. $\mathrm{Li}^{1,2,3}$

\begin{abstract}
${ }^{1}$ Department of Pathology and Laboratory Medicine, Children's Hospital of Philadelphia, Philadelphia, Pennsylvania 19104, USA; ${ }^{2}$ Perelman School of Medicine, University of Pennsylvania, Philadelphia, Pennsylvania 19104, USA; ${ }^{3}$ Division of Oncology, ${ }^{4}$ Division of Neurosurgery, Department of Pediatrics, Children's Hospital of Philadelphia, Philadelphia, Pennsylvania 19104, USA
\end{abstract}

Corresponding author: lim5@email.chop.edu

(C) 2020 Zhong et al. This article is distributed under the terms of the Creative Commons Attribution-NonCommercial

License, which permits reuse and redistribution, except for commercial purposes, provided that the original author and source are credited.

Ontology term: glioma

Published by Cold Spring Harbor Laboratory Press

doi:10.1101/mcs.a005397

\begin{abstract}
PALB2 (partner and localizer of BRCA2) gene encodes a protein that colocalizes with BRCA2 in nuclear foci and likely permits the stable intranuclear localization and accumulation of BRCA2. PALB2 plays a critical role in maintaining genome integrity through its role in the Fanconi anemia and homologous recombination DNA repair pathways. It has a known loss-of-function disease mechanism. Biallelic PALB2 pathogenic variants have been described in autosomal recessive Fanconi anemia. Heterozygous pathogenic variants in PALB2 are associated with increased risk for female and male breast cancer and pancreatic cancer (Science 324: 217; Cancer Res 71: 2222-2229; $N$ Engl J Med 371: 497-506). Heterozygous germline PALB2 mutations have also been observed in patients with medulloblastoma (Lancet Oncol 19: 785-798). However, PALB2-related cancer predisposition to high-grade gliomas has not been reported. Here we report a germline PALB2 pathogenic variant (c.509_510delGA, p.Arg170llefs*14, NM_024675.3) found in a pediatric patient with high-grade glioma. This variant was first identified by tumor sequencing using the Children's Hospital of Philadelphia (CHOP) Comprehensive Solid Tumor Panel and then confirmed to be a germline change using the CHOP Comprehensive Hereditary Cancer Panel on DNA from a blood sample of this patient. Parental studies showed that this variant was paternally inherited. Further studies are needed to illustrate if pathogenic variants in PALB2 convey increased risk to developing brain tumor. This case also highlights the potential of identifying germline mutation through tumor sequencing.
\end{abstract}

\section{CASE PRESENTATION}

The patient was a 7-yr-old female who was diagnosed with anaplastic astrocytoma, isocitrate dehydrogenase (IDH)-wild type, World Health Organization (WHO) grade III involving brainstem, thalamus, cerebellum, and cervical spinal cord (Fig. 1A). The patient's family history was notable for a glioblastoma in maternal grandfather, lung cancer in maternal great grandfather, and gastrointestinal cancers in multiple paternal fourth-degree relatives. 
A

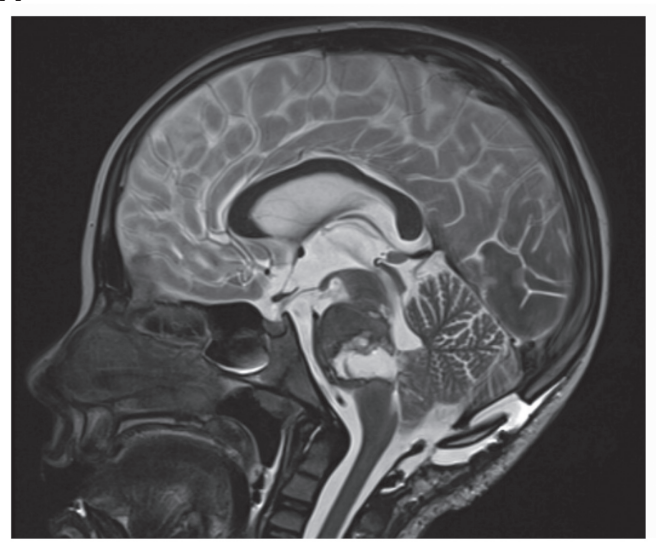

B

\begin{tabular}{|c|c|c|c|}
\hline Chromosome & Abnormality & Band & Genes \\
\hline $\mathrm{X}$ & LOSS & $\begin{array}{c}\text { whole } \\
\text { chromosome }\end{array}$ & \\
\hline 2 & AMP & partial $2 \mathrm{p}$ & MYCN \\
\hline 9 & LOSS & $9 \mathrm{p}$ & CDKN2A \\
\hline \multirow{2}{*}{9} & LOSS & partial 9q & $\begin{array}{c}\text { GNAQ, NTRK2, FANCC, } \\
\text { PTCH1 (homozygous } \\
\text { loss of exons 3-18) }\end{array}$ \\
\hline \multirow{2}{*}{13} & LOSS & partial 13q & RB1 (Homozygous) \\
\hline \multirow{2}{*}{17} & LOSS & $17 p$ & TP53 \\
\cline { 2 - 5 } & LOSS & partial 17q & NF1...PPM1D \\
\cline { 2 - 5 } & cnLOH & partial 17q & BRIP...RPTOR \\
\hline 19 & LOSS & $\begin{array}{c}\text { whole } \\
\text { chromosome }\end{array}$ & \\
\hline 21 & GAIN & $21 q$ & RUNX1 AMP \\
\hline
\end{tabular}

Figure 1. (A) T2-weighted imaging sagittal plane image showing pontine mass with evidence of intratumoral hemorrhage. (B) Copy-number variations (CNVs) identified in the tumor.

\section{TECHNICAL ANALYSIS}

\section{Next-Generation Sequencing (NGS)}

Two-hundred and thirty-eight genes associated with pediatric solid tumors were selected for the Children's Hospital of Philadelphia (CHOP) Comprehensive Solid Tumor Panel (CSTP) (Surrey et al. 2019). Custom DNA probes were designed using SureDesign (Agilent Technologies) to cover all exons, at least $10 \mathrm{bp}$ of intronic sequences at exon/intron boundaries, and selected known intronic mutations. The CHOP Comprehensive Hereditary Cancer Panel (CHCP) interrogates 130 genes associated with cancer predisposition and covers all coding exons, at least 20 bp of intronic sequences at exon/intron boundaries, and known intronic mutations. Additional common single-nucleotide polymorphisms (SNPs) were added to both CSTP and CHCP to mimic a low-density SNP array for copy-number variation (CNV) analysis (Surrey et al. 2019). All custom DNA probes were synthesized and biotinylated to allow for target enrichment using streptavidin-conjugated beads (Agilent Technologies). For target RNA sequencing, 110 major fusion partner genes associated with cancer-related fusions were selected for the CHOP fusion panel (Chang et al. 2019). Multiplex polymerase chain reaction (PCR) technology, powered by unidirectional genespecific primers, sample indexes, and molecular barcodes for multiplex targeted RNA sequencing (ArcherDX, Inc.), were used. Target-specific primers covering 673 exons were custom-designed to identify known fusions and potential novel fusions associated with 110 cancer genes.

Multiple clinically significant alterations were detected in the tumor, including TP53 (c.724T>A, p.Cys242Ser), NF1 (c.6854dup, p.Tyr2285*), PALB2 (c.509_510delGA, p.Arg170llefs*14) (Table 1), MYCN amplification, and multiple other CNVs including loss of Chromosome 17 (Fig. 1B). No known or novel fusion genes were detected. The variant allele fractions (VAFs) were $0.75,0.79$, and 0.43 for the TP53, NF1, and PALB2 variants, respectively. Further NGS studies using the CHCP on DNA from a blood sample of this patient was performed and identified the same PALB2 c.509_510delGA pathogenic variant, demonstrating a germline change, along with pre- and post-testing genetic counseling. No other somatically identified variant was detected in the blood. Targeted sequencing of parental samples showed that this variant was paternally inherited. 
Table 1. Sequence variants identified in the tumor and blood

\begin{tabular}{|c|c|c|c|c|c|c|c|c|c|}
\hline Gene & Chr & $\begin{array}{l}\text { HGVS DNA ref } \\
\text { (if genic) }\end{array}$ & $\begin{array}{l}\text { HGVS protein } \\
\text { ref }\end{array}$ & $\begin{array}{l}\text { Variant } \\
\text { type }\end{array}$ & $\begin{array}{l}\text { Predicted } \\
\text { effect }\end{array}$ & $\begin{array}{c}\text { Allele } \\
\text { frequency }\end{array}$ & $\begin{array}{c}\text { Target } \\
\text { coverage }\end{array}$ & Present in & $\begin{array}{c}\text { Germline/ } \\
\text { somatic }\end{array}$ \\
\hline PALB2 & 16 & c.509_510delGA & p.Arg170llefs*14 & Deletion & Frameshift & $43 \%$ & $2303 x$ & Tumor/blood & Germline \\
\hline TP53 & 17 & c. $724 \mathrm{~T}>\mathrm{A}$ & p.Cys242Ser & SNV & Deleterious & $75 \%$ & $842 x$ & Tumor & Somatic \\
\hline NF1 & 17 & c.6854dup & p.Tyr2285* & Duplication & Nonsense & $79 \%$ & $220 x$ & Tumor & Somatic \\
\hline
\end{tabular}

(HGVS) Human Genome Variation Society, (SNV) single-nucleotide variant.

\section{VARIANT INTERPRETATION}

The PALB2 c.509_510delGA variant creates a frameshift starting at codon Arg170 in exon 4, which results in a premature stop codon 14 amino acids downstream. The variant is observed in the genome Aggregation Database (gnomAD) with an allele frequency of $0.003579 \%$ (9/251446, 0 homozygotes) and it has been identified as a germline variant in patients with ovarian cancer, breast cancer, and pancreatic ductal adenocarcinoma (DansonkaMieszkowska et al. 2010; Noskowicz et al. 2014; Borecka et al. 2016). The variant is reported in ClinVar (Variation ID 126757) and listed as pathogenic by 15 submissions. It is not reported in the Catalogue of Somatic Mutations in Cancer (COSMIC).

\section{SUMMARY}

A germline PALB2 pathogenic variant (c.509_510delGA) was confirmed in a patient with a pediatric high-grade glioma after finding the variant in somatic tumor sequencing. Although it is not clear at the present time if the PALB2 c.509_510delGA variant is associated with the brain tumor development in this patient, heterozygous germline BRCA1 or BRCA2 pathogenic variants have been reported in patients with brain tumors (Wilson et al. 2010; Shoua et al. 2018). Additionally, two somatic PALB2 variants have been previously observed in high-grade gliomas (Mackay et al. 2017). Further functional studies are needed to explore if PALB2 pathogenic variants predispose mutation carriers to central nervous system (CNS) tumors.

\section{ADDITIONAL INFORMATION}

\section{Data Deposition and Access}

The interpreted variant has been deposited in ClinVar (https://www.ncbi.nlm.nih.gov/ clinvar/) under accession number VCV000126757.11. Other variants identified in the 238 gene in the CHOP Comprehensive Solid Tumor Panel and 130 genes in the Comprehensive Hereditary Cancer Panel are reported in the body of the manuscript. The patient did not provide consent for public deposition of all raw sequencing data.

\section{Ethics Statement}

A case report does not constitute human subjects research. Per CHOP policy, it therefore does not require IRB review. 
COLD SPRING HARB OR Molecular Case Studies
A germline PALB2 variant in a pediatric glioma
Competing Interest Statement

The authors have declared no competing interest.

Received March 18, 2020 accepted in revised form May 18,2020

\section{Author Contributions}

M.M.L. and Y.Z. designed the study. M.M.L., Y.Z., J.S., J.W., F.X., F.L., K.C., K.Z., M.L., and S.P.M. collected and analyzed the data. M.M.L., Y.Z., J.S., J.W., and F.X. wrote the manuscript. J.B.F., K.A.C., and P.B.S. provided clinical data. M.M.L., Y.Z., J.S., J.W., F.X., F.L., K.C., K.Z., M.L., J.B.F., K.A.C., S.P.M., A.C.R., and P.B.S. reviewed the manuscript.

\section{Funding}

The study is partially supported by the Department of Pathology and Laboratory Medicine and Center for Childhood Cancer Research, Children's Hospital of Philadelphia and National Institutes of Health (NIH) grant U2CHL138346 (A.C.R., P.B.S., and M.M.L.).

\section{REFERENCES}

Borecka M, Zemankova P, Vocka M, Soucek P, Soukupova J, Kleiblova P, Sevcik J, Kleibl Z, Janatova M. 2016. Mutation analysis of the PALB2 gene in unselected pancreatic cancer patients in the Czech Republic. Cancer Genet 209: 199-204. doi:10.1016/j.cancergen.2016.03.003

Chang F, Lin F, Cao K, Surrey L F, Aplenc R, Bagatell R, Resnick A C, Santi M, Storm P B, Tasian S K, et al. 2019. Development and clinical validation of a large fusion gene panel for pediatric cancers. J Mol Diagn 21: 873-883. doi:10.1016/j.jmoldx.2019.05.006

Dansonka-Mieszkowska A, Kluska A, Moes J, Dabrowska M, Nowakowska D, Niwinska A, Derlatka P, Cendrowski K, Kupryjanczyk J. 2010. A novel germline PALB2 deletion in Polish breast and ovarian cancer patients. BMC Med Genet 11: 20. doi:10.1186/1471-2350-11-20

Jones S, Hruban R H, Kamiyama M, Borges M, Zhang X, Parsons D W, Lin J C, Palmisano E, Brune K, Jaffee E M, et al. 2009. Exomic sequencing identifies PALB2 as a pancreatic cancer susceptibility gene. Science 324: 217. doi:10.1126/science.1171202

Mackay A, Burford A, Carvalho D, Izquierdo E, Fazal-Salom J, Taylor K R, Bjerke L, Clarke M, Vinci M, Nandhabalan M, et al. 2017. Integrated molecular meta-analysis of 1000 pediatric high-grade and diffuse intrinsic pontine glioma. Cancer Cell 32: 520-537 e525. doi:10.1016/j.ccell.2017.08.017

Noskowicz M, Bogdanova N, Bermisheva M, Takhirova Z, Antonenkova N, Khusnutdinova E, Bremer M, Christiansen H, Park-Simon TW, Hillemanns P, et al. 2014. Prevalence of PALB2 mutation c.509 510delGA in unselected breast cancer patients from Central and Eastern Europe. Fam Cancer 13: 137-142. doi:10.1007/s10689-013-9684-1

Shoua B, Tangonan K, Coleman J, Cobos E. 2018. Occurrence of glioblastoma multiforme in BRCA-1 positive women. J Invest Med 66: A271.

Surrey L F, MacFarland S P, Chang F, Cao K, Rathi K S, Akgumus G T, Gallo D, Lin F, Gleason A, Raman P, et al. 2019. Clinical utility of custom-designed NGS panel testing in pediatric tumors. Genome Med 11: 32 doi:10.1186/s13073-019-0644-8

Wilson B T, Douglas S F, Polvikoski T. 2010. Astrocytoma in a breast cancer lineage: part of the BRCA2 phenotype? J Clin Oncol 28: e596-e598. doi:10.1200/JCO.2010.28.9173 


\section{COLD SPRING HARBOR Molecular Case Studies}

\section{A germline PALB2 pathogenic variant identified in a pediatric high-grade glioma}

Yiming Zhong, Jeffrey Schubert, Jinhua Wu, et al.

Cold Spring Harb Mol Case Stud 2020, 6: a005397 originally published online June 18, 2020 Access the most recent version at doi: $10.1101 / \mathrm{mcs} .0005397$

References This article cites 9 articles, 2 of which can be accessed free at: http://molecularcasestudies.cshlp.org/content/6/4/a005397.full.html\#ref-list-1

License This article is distributed under the terms of the Creative Commons Attribution-NonCommercial License, which permits reuse and redistribution, except for commercial purposes, provided that the original author and source are credited.

Email Alerting Receive free email alerts when new articles cite this article - sign up in the box at the Service top right corner of the article or click here. 